\title{
三峡库区消落带不同水位高程植被和土壤特征差异”
}

\author{
王业春, 雷 波, 张 晟 ${ }^{* *}$ \\ (重庆环境科学研究院,重庆 401147)
}

\begin{abstract}
摘 要: 植被和土壤是消落带生态系统的重要组成部分. 本研究选择三峡库区腹地忠县境内的 3 个地质地貌和土地利用 历史相似的近自然消落带, 对不同水位高程 $(160 \mathrm{~m}$ 和 $170 \mathrm{~m})$ 植被群落和土壤特征进行研究, 结果表明: 一年生草本在消 落带植物物种数中比例高达 $72.4 \%$, 而多年生草本仅为 $27.6 \%$; 不同水位高程植被物种组成完全相同, 且盖度、生物量、 生物多样性指数均没有显著差异; 随着水位高程变化, 群落优势物种存在一定差异, 即 $160 \mathrm{~m}$ 高程优势种为多年生狗牙根 (Cynodon dactylon), 而 $170 \mathrm{~m}$ 高程为一年生白酒草 (Conyza japonica); 土壤容重、含水量、 $\mathrm{pH}$ 、有机质、总氮、总磷在 $160 \mathrm{~m}$ 和 $170 \mathrm{~m}$ 水位高程间均没有显著差异. 因此, $160 \mathrm{~m}$ 和 $170 \mathrm{~m}$ 水位高程在淹水时间和深度上的差异造成群落优势种的不 同,而对当前植被和土壤特征并没有显著影响.
\end{abstract}

关键词: 三峡库区;消落带;水位高程;植被;土壤

\section{Differences in vegetation and soil characteristics at different water-level altitudes in the drawdown areas of Three Gorges Reservoir area}

\author{
WANG Yechun, LEI Bo \& ZHANG Sheng \\ (Chongqing Academy of Environmental Science, Chongqing 401147, P. R. China)
}

\begin{abstract}
Vegetation and soil are the key components of the drawdown area of Three Gorges Reservoir. To investigate characteristics of vegetation and soil from water-level altitude of $160 \mathrm{~m}$ and $170 \mathrm{~m}$, three drawdown areas with similar geological environment and history of land-use in Zhongxian County were chosen. Results indicated that percent of annual and perennial herbaceous species in drawdown area were $72.4 \%$ and $27.6 \%$, respectively. There were no significant differences in species composition, coverage, biomass and biodiversity index between $160 \mathrm{~m}$ and $170 \mathrm{~m}$. With water-level altitude changing, the dominant species of plant community varied. Cynodon dactylon was the dominant species at $160 \mathrm{~m}$, while Conyza japonica at $170 \mathrm{~m}$. Soil bulk density, water content, $\mathrm{pH}$, SOM, TN and TP at $160 \mathrm{~m}$ and $170 \mathrm{~m}$ did not differ significantly. Therefore, it seems reasonable to suggest that their different dominant species resulted from the different inundation period and water depth in those areas between $160 \mathrm{~m}$ and $170 \mathrm{~m}$, which did not play a significant role in current vegetation and soil development.
\end{abstract}

Keywords: Three Gorges Reservoir area; drawdown areas; water-level altitude; vegetation; soil

三峡水库 2009 年全面建成, 根据“蓄清排浊” 的水位调度方案及目前实际运行结果, 库区已形成大面积 的消落带, 成为我国最大的人工湿地, 其生态环境特征与黄河流域等其他大型水库消落带、自然湿地相比, 存在三个显著特征: 1$)$ 水位落差大 $(30 \mathrm{~m})$, 淹水时间长且存在明显淹水梯度;2) 水位涨落节律与蓄水前的 自然消落带完全相反, 即冬水夏陆; 3 ) 面积大, 分布区域广泛且周围城镇密集, 消落带生态系统干扰频 繁 ${ }^{[1-2]}$. 然而消落带是影响三峡水库生态环境安全的关键区域之一 ${ }^{[3]}$, 对水土流失、养分循环和非点源污染 有着显著的缓冲和过滤作用, 并对维持较高的生物生产力和生物多样性等具有积极作用, 也是三峡库区水 质安全保障的屏障 ${ }^{[4]}$. 因此三峡库区消落带的生态环境引起国内外的广泛关注 ${ }^{[5-6]}$.

目前关于三峡库区消落带植被和土壤的研究分别集中在植被恢复与重建 ${ }^{[7-9]}$, 淹水前后消落带土壤养

* 国家水体污染控制与治理科技重大专项项目 (2009ZX07104-003-01) 资助. 2011-10-14 收稿; 2011-11-13 收修 改稿.王业春,男,1980 年生,博士;E-mail: wangyechun@ yahoo. com.

** 通信作者; E-mail: shengzsts@126.com. 
分及重金属模拟与调查研究 ${ }^{[10-13]}$ 等方面. 如孙荣等 ${ }^{[14]}$ 调查分析了三峡库区澎溪河开县段植物群落物种多样 性随水位高程的变化梯度及空间格局. 常超等 ${ }^{[15]}$ 研究了三峡工程蓄水对库区土壤理化特性及养分含量的影 响. 过去研究大都集中在 2008 年或 2009 年 $175 \mathrm{~m}$ 蓄水前 ${ }^{[15-16]}$, 而 $175 \mathrm{~m}$ 蓄水后的研究很少. 相关研究表明 消落带的植被和土壤特性除受到水文条件变化影响以外 ${ }^{[17-18]}$, 还受地形、土壤质地、人为干扰 ${ }^{[19-21]}$ 等影响. 然而以往的研究, 尤其是野外研究并没有充分考虑或规避这些因素 ${ }^{[4,10,22]}$. 因此, 本研究选择 3 个地质地貌 特征、土地利用历史等相似的近自然状态消落带, 研究不同水位高程消落带生态系统中植被和土壤特征及 差异来揭示水库高水位运行后消落带现状,拟为三峡水库消落带的科学管理提供理论支持.

\section{1 研究区概况与研究方法}

\section{1 研究区概况与消落带选择}

忠县 $\left(30^{\circ} 03^{\prime} 03^{\prime \prime} \sim 30^{\circ} 35^{\prime} 35^{\prime \prime} \mathrm{N}, 107^{\circ} 32^{\prime} 42^{\prime \prime} \sim 108^{\circ} 14^{\prime} 00^{\prime \prime} \mathrm{E}\right)$ 地处三峡库区腹部, 长江由西南向东北横贯全境. 该 区属亚热带东南季风气候, 年平均气温 $18.2^{\circ} \mathrm{C},>10^{\circ} \mathrm{C}$ 的年积温为 $5891.4^{\circ} \mathrm{C}$, 年均降雨量为 $1172.1 \mathrm{~mm}$, 多 集中在 6-8 月 ${ }^{[23]}$. 为了减少土壤类型、地形地貌、人类活动干扰等对植被和土壤的影响, 本文选择 3 个坡 度、坡向、土地利用历史等相似的近自然状态消落带 (彼此间隔 $>0.5 \mathrm{~km}$ ). 各消落带基本情况详见表 1 .

表 1 消落带的基本情况

Tab. 1 Fundamental information of three drawdown areas

\begin{tabular}{ccccc}
\hline 消落带 & 位置 & 坡向 & 坡度/ & 土地利用历史/土壤类型 \\
\hline 消落带 1 & $30^{\circ} 15^{\prime} 14^{\prime \prime} \mathrm{N}, 107^{\circ} 59^{\prime} 53^{\prime \prime} \mathrm{E}$ & $10.1 \mathrm{NW}$ & 44.5 & 农业耕地/黄壤 \\
消落带 2 & $30^{\circ} 14^{\prime} 31^{\prime \prime} \mathrm{N}, 108^{\circ} 00^{\prime} 04^{\prime \prime} \mathrm{E}$ & $10.8 \mathrm{NW}$ & 51.3 & 农业耕地/黄壤 \\
消落带3 & $30^{\circ} 13^{\prime} 53^{\prime \prime} \mathrm{N}, 108^{\circ} 00^{\prime} 06^{\prime \prime} \mathrm{E}$ & $8.7 \mathrm{NW}$ & 43.4 & 农业耕地/黄壤 \\
\hline
\end{tabular}

\section{2 野外植物群落调查与土壤取样}

三峡水库水位调度使得不同水位高程间 淹水时间和深度上存在明显差异. 考虑到取 样时期为三峡水库洪水调度阶段,水位大都在 $140 \sim 155 \mathrm{~m}$ 波动(图 1), 因此本研究只设置了 2 个水位高程: $160 \mathrm{~m}$ (范围为 $158 \sim 162 \mathrm{~m}$ ) 和 $170 \mathrm{~m}$ (范围为 $168 \sim 172 \mathrm{~m}$ ). 2010 年 8 月 $25-31$ 日, 每个消落带在不同水位高程范围 内沿河流方向设置一条 $200 \mathrm{~m}$ 的样线, 然后 等距离布置 10 个 $1 \mathrm{~m} \times 1 \mathrm{~m}$ 草本样方, 用于草 本群落调查. 由于蓄水前人为清库, $175 \mathrm{~m}$ 以 内乔木和灌木已被清除, 目前消落带内基本 为草本植物 ${ }^{[5]}$, 所以野外植被调查只涉及到 草本. 首先调查样方内植物总盖度、植物物种

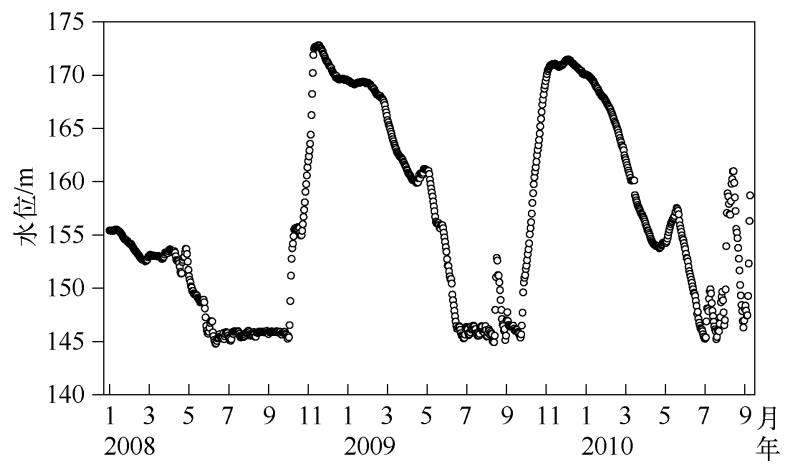

图 1 三峡大坝坝前水位波动 ${ }^{[24]}$

Fig. 1 Water-level fluctuation in front of Three Gorges Dam (Jan. , 2008 - Aug. , 2010) 名、密度、物种盖度、高度等, 随后对样方内所 有植株地上部分进行刚割, 称量其鲜重, 并取全部或部分鲜样带回实验室待烘干. 同时在每条样线上采用多 点混合取样法分层 $(0 \sim 10 \mathrm{~cm}$ 和 $10 \sim 20 \mathrm{~cm})$ 采集土壤, 每高程同层土壤共收集 3 个混合样. 三个消落带共调 查 90 个草本样方, 采集 36 个土壤样品.

\section{3 多样性指数 ${ }^{[25]}$}

(1) Patrick 丰富度指数 $R=S$; (2) 辛普森 (Simpson) 多样性指数 $(D): D=1-\sum_{i=1}^{s} P_{i}^{2}$; (3) 香农一威纳 (Shannon-Wiener) 指数 $(H): H=-\sum_{i=1}^{s} P_{i} \ln P_{i} ;$ （4) Pielou 均匀度指数 $E=H / \ln S$. 式中, $P_{i}$ 为物种 $i$ 的重要值; 
$S$ 为物种数 $; i=($ 相对盖度 + 相对密度 + 相对频度 $) \times 100 / 3$

\section{4 样品处理与分析}

采集的植物样品用烘干法 $\left(75^{\circ} \mathrm{C}, 48 \mathrm{~h}\right)$ 测定其干重, 推算样方草本地上生物量干重. 对于土壤样品,待 其风干后去除杂物及石块, 经过玛瑙研针处理后过 100 目尼龙篮,䛎存在塑料自封袋. 土壤分析测试指标及 其方法: 含水量 (烘干法 $\left(105^{\circ} \mathrm{C}, 12 \mathrm{~h}\right)$ )、容重 (环刀法)、 $\mathrm{pH}$ ( 玻璃电极法)、有机质 ( $\mathrm{SOM}$, 重铬酸钾容量法)、 总氮 ( TN, 半微量凯氏法) 和总磷 ( TP, $X$ 射线苂光光谱法 $\left.{ }^{[26]}\right)$.

\section{5 数据统计与分析}

不同高程 (160 m 和 $170 \mathrm{~m}$ ) 植被生物量 (鲜重和干重)、盖度、多样性指数、土壤理化和养分含量的差异 分析采用非参数的两两比较. 土壤理化及养分含量相关关系采用 Spearman 相关分析, 所有统计分析运用 SPSS 17.0 进行处理.

\section{2 结果与分析}

\section{1 消落带不同高程植被的生物学特征}

2.1 .1 植被组成、生物量和盖度 三个消落带共出现 98 个物种,分属于 28 科、69 属. 其中以菊科 (18 种) 和 禾本科 (13 种) 为优势科, 分别占总物种的 $18.4 \% 、 13.3 \%$. 多年生草本仅 27 种占 $27.6 \%$,而一年生草本 71 种占 $72.4 \%$.

尽管 $160 \mathrm{~m} 、 170 \mathrm{~m}$ 高程淹水时间分别为 334 和 $90 \mathrm{~d}$, 存在明显差异 (图 1), 但群落物种组成却完全相 同, 即 98 个物种在两高程中均出现. $160 \mathrm{~m}$ 高程群落鲜重和干重分别为 $1.36 \pm 0.34 、 0.53 \pm 0.11 \mathrm{~kg} / \mathrm{m}^{2}, 170 \mathrm{~m}$ 高程群落鲜重和干重分别为 $0.84 \pm 0.11 、 0.38 \pm 0.04 \mathrm{~kg} / \mathrm{m}^{2}$, 不同高程群落的鲜重和干重间均没有显著差 异; 与群落生物量一样, 不同高程群落盖度 $(160 \mathrm{~m}$ 和 $170 \mathrm{~m}$ 分别为 $68.9 \% \pm 5.9 \%$ 和 $66.6 \% \pm 5.2 \%$ ) 也没有 显著差异.

表 2 不同水位高程 $(160 \mathrm{~m}$ 和 $170 \mathrm{~m})$ 物种重要值

Tab. 2 The values of species with different water-level altitudes $(160 \mathrm{~m}$ and $170 \mathrm{~m})$

\begin{tabular}{clcc}
\hline \multirow{2}{*}{ 编号 } & \multicolumn{1}{c}{ 物种名 } & \multicolumn{2}{c}{ 物种重要值 } \\
\cline { 3 - 4 } & & $160 \mathrm{~m}$ & $170 \mathrm{~m}$ \\
\hline \multirow{2}{*}{1} & 白酒草( Conyza japonica) & 8.2 & 20.6 \\
2 & 苍耳(Xanthium sibiricum) & 8.8 & 7.9 \\
3 & 狗尾草( Setaria viridis) & 6.7 & 7.0 \\
4 & 狗牙根( Cynodon dactylon) & 24.8 & 17.7 \\
5 & 金色狗尾草( Setaria glauca) & 7.4 & - \\
6 & 两岐飘拂草( Fimbristylis dichotoma) & 0.3 & 4.1 \\
7 & 马唐(Digitaria sanguinalis) & 3.7 & - \\
8 & 石荠苦(Mosla scabra) & - & 4.3 \\
9 & 小蓬草( Conyza canadensis) & 4.8 & 7.9 \\
10 & 野秘(Eriochloa villosa) & 4.7 & 8.8 \\
11 & 益母草( Leonurus japonicus) & - & 2.5 \\
12 & 酢浆草( Oxalis corniculata) & 3.7 & 3.4 \\
合计 & & 76.2 & 84.4 \\
\hline
\end{tabular}

2.1 .2 生物多样性和物种重要值 $160 \mathrm{~m}$ 和 $170 \mathrm{~m}$ 高程的 Patrick 丰富度指数为 $11.3 \pm$ $0.3 、 13.0 \pm 0.9$, Simpson 多样性指数分别为 $0.80 \pm 0.03 、 0.80 \pm 0.02$, Shannon-Wiener 指 数为 $2.0 \pm 0.1 、 2.1 \pm 0.1$, Pielou 均匀度指数 分别为 $0.81 \pm 0.03 、 0.80 \pm 0.02$, 四个多样 性指数在两高程间均没有显著差异.

$160 \mathrm{~m}$ 和 $170 \mathrm{~m}$ 高程植物群落中重要值 在前 10 位物种中只有狗牙根和酢浆草为多 年生草本外,其他 8 个物种均为一年生草本 (表 2). 随着高程增加,群落优势种出现了变 化, $160 \mathrm{~m}$ 和 $170 \mathrm{~m}$ 高程优势物种分别为多 年生狗牙根和一年生草本白酒草. 优势种狗 牙根重要值由 24.8 (160 m 高程) 降至 17.7 ( $170 \mathrm{~m}$ 高程). 与狗牙根相反, 白酒草重要值 在 $160 \mathrm{~m}$ 高程仅为 8.2 , 而在 $170 \mathrm{~m}$ 高程突 然增至 20.6 , 因此成为该高程优势种 (表2).

\section{2 消落带不同高程土壤特征}

除了 $160 \mathrm{~m}$ 高程 $0 \sim 10 \mathrm{~cm}$ 层土壤有机质明显高于 $10 \sim 20 \mathrm{~cm}$ 外,不同高程 $(160 \mathrm{~m}$ 和 $170 \mathrm{~m}$ ) 及其不同 土壤层 $(0 \sim 10 \mathrm{~cm}$ 和 $10 \sim 20 \mathrm{~cm})$ 间土壤容重、含水量、 $\mathrm{pH}$ 、有机质、总氮和总磷均无显著差异 (图 2$)$. 土壤含 水量与容重呈显著负相关 $(P<0.05)$, 而与土壤有机质和总氮呈显著正相关 $(P<0.05)$; 土壤容重与有机质 和总氮呈显著负相关 $(P<0.05)$; 土壤总氮与有机质呈显著正相关 $(P<0.05)$; 总磷相对独立, 与其他土壤 
参数均没有显著相关性 $(P>0.05)($ 表 3$)$.
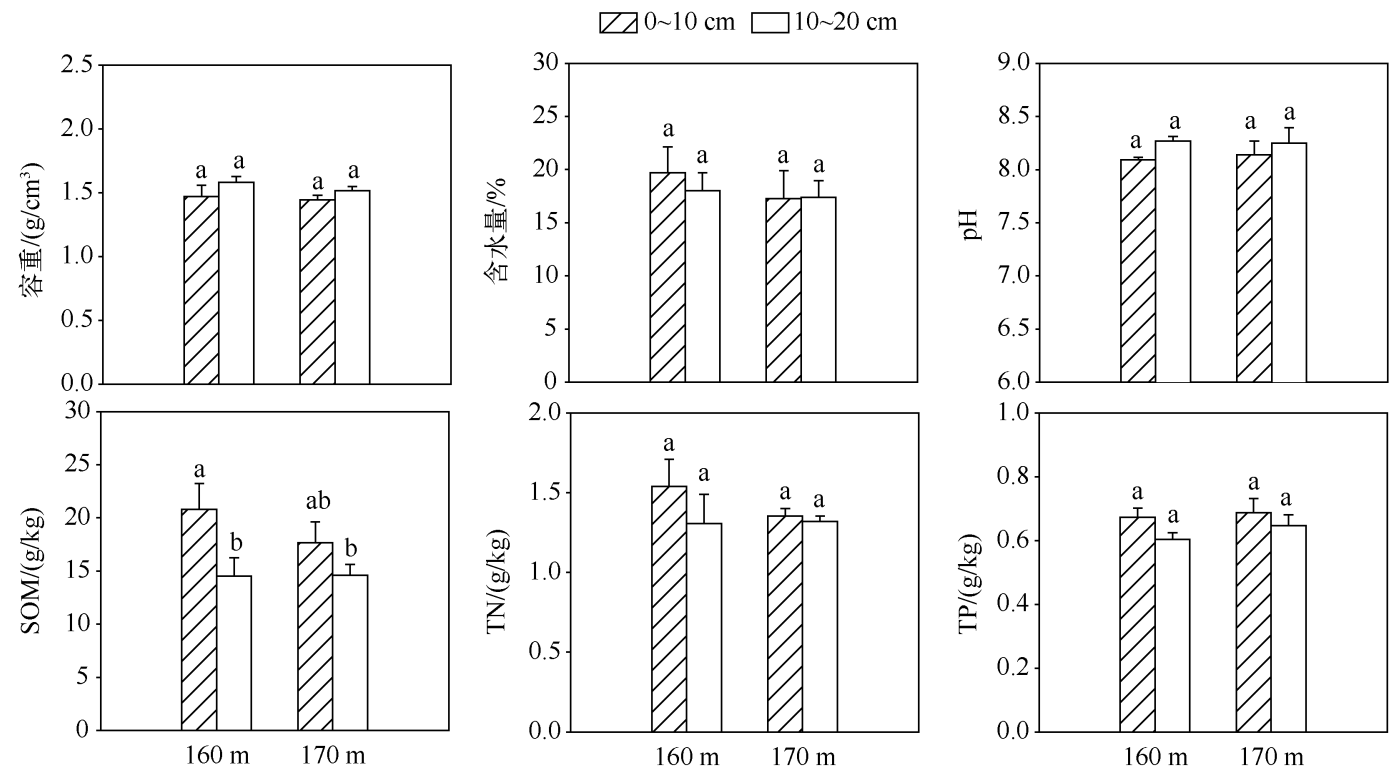

图 2 不同水位高程 $(160 \mathrm{~m}$ 和 $170 \mathrm{~m})$ 土壤容重、含水量、 $\mathrm{pH} 、 \mathrm{SOM}$ 、TN 和 TP

Fig. 2 The content of soil bulk density, water content, $\mathrm{pH}, \mathrm{SOM}$, TN and TP with different water-level altitudes $(160 \mathrm{~m}$ and $170 \mathrm{~m})$

表 3 土壤含水量、容重、 $\mathrm{pH}$ 、有机质、总氮和总磷的相关关系

Tab. 3 The correlationship between soil water content, bulk density, pH, SOM, TN and TP

\begin{tabular}{ccccccc}
\hline 相关因子 & 含水量 & 容重 & $\mathrm{pH}$ & $\mathrm{SOM}$ & $\mathrm{TN}$ & $\mathrm{TP}$ \\
\hline 含水量 & 1.000 & & & & & \\
容重 & $-0.756^{* *}$ & 1.000 & & & & \\
$\mathrm{pH}$ & 0.394 & -0.056 & 1.000 & & & \\
$\mathrm{SOM}$ & $0.494^{*}$ & $-0.426^{*}$ & -0.123 & 1.000 & & \\
$\mathrm{TN}$ & $0.431^{*}$ & $-0.575^{* *}$ & -0.114 & $0.508^{*}$ & 1.000 & \\
$\mathrm{TP}$ & -0.196 & -0.082 & 0.366 & 0.015 & -0.056 & 1.000 \\
\hline
\end{tabular}

*表示 $P<0.05 ; * *$ 表示 $P<0.01$.

\section{3 讨论}

\section{1 消落带植被特征及高程差异}

研究结果表明三峡库区消落带物种组成以一年生草本植物 (物种比例为 $72.4 \%$ ) 为主, 国内外其它相关 研究也证实了这一结论 ${ }^{[9,14,29]}$. 白宝伟等 ${ }^{[27]}$ 在研究三峡库区自然消落带发现草本中一年生草本占 $40 \% \sim$ $48 \%$, 而蓄水后消落带一年生草本植物的比例有所增加. 同样在研究淹水对剓归消落带植被组成影响时发 现, 淹没区一年生草本占 $52 \%$, 多年生草本占 $29 \%$, 而未淹没区分别为 $20.5 \% 、 36.36 \%{ }^{[9]}$, 这意味着淹水提 高了一年生植物的比例 ${ }^{[29-30]}$. 导致这种现象的主要原因可能与不同生活型草本植物对水淹的响应和适应不 同有关:一方面一年生草本植物主要靠种子繁殖, 其特点是生活史短、繁殖力强, 最能适应持久和强度干 扰 $^{[31]}$; 其次, 一年生草本植物生活周期短, 其生长发育时期正好与消落带成陆期一致. 即使在三峡消落带出 露时间较短的低水位高程, 也可以完成从萌发到开花结果的生活过程, 且能够在退水后蓄水前完成其生活 
史, 次年依靠土壤种子库或者临近种源开始新的生长周期. 因此,一年生草本植物能够很好地利用和适应消 落带的这种反季节淹水与成陆的动态变化 ${ }^{[9]}$. 另一方面多年生植物需要长时间来完成整个生命周期, 在淹 水情况尤其是完全淹水情况下大都难以存活 ${ }^{[14]}$. 但有些多年生植物通过地上匍匐茎或地下根状茎( 如狗牙 根、牛鞭草 Hemarthria altissima), 这些耐水淹的多年生植物种类较少且大都集中分布在消落带较低高程内. 因此,一年生植物和多年生植物对水淹的适应与响应共同造成了一年生植物在群落中的较高比例.

$160 \mathrm{~m}$ 和 $170 \mathrm{~m}$ 群落基本参数 (盖度、生物量、多样性指数) 没有显著差异, 可能与两高程间物种组成相 同有关. 群落以一年生植物为主, 一年生草本植物能够很好地利用和适应消落带的蓄水与出露的动态变 化 ${ }^{[9]}$. 本研究中 $160 \mathrm{~m}$ 和 $170 \mathrm{~m}$ 高程在野外调查时已经历了约 $190 \mathrm{~d}(3-9$ 月) 和 $270 \mathrm{~d}(1-10$ 月) 落干, 这 足以让各高程消落带草本植物完成其萌芽、定居、生长或繁殖过程, 最终导致 $160 \mathrm{~m}$ 和 $170 \mathrm{~m}$ 高程群落盖度、 生物量、多样性指数没有显著差异.

随着高程增加, 群落优势种出现了变化, 即 $160 \mathrm{~m}$ 高程优势种为多年生狗牙根而在 $170 \mathrm{~m}$ 高程被一年生 白酒草替代. 三峡库区其它区域的消落带也存在相似的现象. 如孙荣等 ${ }^{[14]}$ 和王强等 ${ }^{[16]}$ 在研究澎溪河流域消 落带植被组成时发现, 随高程增加各梯度植物群落发生明显变化, 各群落优势种从适应水生的水苶( Polygonum hydropiper) 等过渡到陆生的白茅( Imperata cylindrica), 伴生种也由扁穗牛鞭草 (Hemarthria compressa) 等 湿生植物过渡到苍耳、小白酒草 (Conyza canadensis) 等早生植物. 这显然和不同海拔高程环境有着必然联 系, 特别是水淹时间 ${ }^{[32]}$. 另外, 出现优势物种的替代现象可能与群落内物种间的竞争结果变化有着密切关 系. 消落带成陆初期 (如 $170 \mathrm{~m}$ 高程每年 2 月或 3 月开始出露) 气温较低, 草本植物并未返青或萌发, 但随着 气温上升首先是多年生植物返青 ${ }^{[33]}$, 同时一年生草本种子开始萌发. 显然在成陆初期和相当长时间内多年 生草本比一年生草本的竞争能力及种群扩散能力要强, 在此期间群落将会以多年生植物占优势. 随着成陆 时间增加,一年生草本的快速生长与扩张改变了整个群落的微生境, 如光照环境, 使得一年生植物和多年生 植物种间竞争结果发生变化,即在此期间群落将会从多年生占优势逐渐转变为一年生植物占优势. 在本研 究中,多年生狗牙根在成陆时间相对较短的低水位 $160 \mathrm{~m}$ 高程中占据优势地位, 但在出露时间较长的 $170 \mathrm{~m}$ 高程,优势植物变为一年生白酒草.

\section{2 消落带土壤特征及高程差异}

其他流域研究及三峡库区消落带模拟实验发现, 经过淹水, 酸性土壤 $\mathrm{pH}$ 升高, 碱性土壤 $\mathrm{pH}$ 降低. 随着 淹水时间延长, $\mathrm{pH}$ 最终都将趋于中性 ${ }^{[11,34]}$. 但本研究中淹水时间较长的 $170 \mathrm{~m}$ 高程土壤 $\mathrm{pH}$ 与 $160 \mathrm{~m}$ 相比 并没有明显上升或下降. 这种现象的出现可能与本研究的取样时间有关. 水位下降消落带出露后土壤再次 暴露, 形成了一个与淹水还原条件截然相反的氧化环境, 土壤 $\mathrm{pH}$ 可能存在一定的恢复. 到取样时 (8 月底), 因为 $160 \mathrm{~m}$ 和 $170 \mathrm{~m}$ 高程土壤已经历了 $190 \mathrm{~d}$ 落干以上, 导致土壤 $\mathrm{pH}$ 值在不同高程间并没有显著差异. 另 外, 土壤 $\mathrm{pH}$ 一般随土壤含水量增加有升高的趋势, 尤其是酸性土壤 ${ }^{[35]}$. 本研究中 $160 \mathrm{~m}$ 和 $170 \mathrm{~m}$ 高程土壤 含水量也没有明显差异, 从侧面解释了不同高程 $\mathrm{pH}$ 的无差异性.

土壤有机质是土壤稳定性的重要保障 ${ }^{[35]}$. 湿地土壤的有机质主要来源于土壤有机质的矿化和动植物残 体的分解, 其输出主要包括分解和侵蚀损失 ${ }^{[36]}$. 有研究表明土壤经常处于淹水状态, 其氧化还原电位低, 形 成了大量还原性物质, 有利于有机质积累, 再加上淹水缺氧微生物活动受阻, 有机质分解减缓; 而夏季落干 暴露后, 氧气含量增加且温度上升, 微生物活动迅速加强, 促进了有机质分解, 有机质含量最终降低 ${ }^{[4]}$. 在本 研究中 $160 \mathrm{~m}$ 和 $170 \mathrm{~m}$ 高程土壤相同层间并没有显著差异, 可能与不同高程间有机质积累、分解及土壤有机 质本底、地上植被等因素有关,需要进一步深人分析.

总氮与有机质间有着密切相关关系, 因为土壤中氮素主要以有机态存在, 因此有机质含量越高其总氮 含量也越高 ${ }^{[37]}$. 本研究中土壤有机质和总氮也呈显著正相关 $(P<0.05)$. 与土壤氮素不同, 磷素受土壤母质 的影响较大 ${ }^{[38]}$. 相关分析表明土壤总磷与有机质和总氮没有显著相关性 $(P>0.05)$, 同时不同水位高程土 壤总磷也没有显著差异, 这可能与不同高程土壤母质特征基本一致有关. 值得注意的是, 三峡库区消落带土 壤理化特性及养分含量变化是一个受多方面及长时期因素影响的过程 ${ }^{[16]}$, 各种因素的影响方式及影响过程 都有待于进一步研究. 


\section{4 结论}

1 ) 一年生草本物种丰度在消落带群落中占据绝对优势. 这表明与多年生草本相比,一年生草本植物更 能够适应消落带环境变化, 因此对退水后消落带植被的自然恢复具有重要作用.

2) $160 \mathrm{~m}$ 和 $170 \mathrm{~m}$ 高程在淹水时间和深度上的差异导致了各高程优势种的不同, 但对物种组成、生物 量、盖度和多样性指数并没有显著影响.

3 ) 因此从土壤养分全量来看, 不同水位高程土壤对当年三峡库区蓄水水体有机质、氮、磷释放潜力是大 致相同的.

致谢: 重庆环境科学院王目通、重庆师范大学生命科学学院吴江林和龙富波参与了野外植被调查与土壤采 集工作,西南大学园艺学院李先源教授对植被标本进行了鉴定,在此表示感谢!

\section{5 参考文献}

[ 1 ] 中国工程院三峡工程阶段性评估报告项目组. 三峡工程阶段性评估报告: 综合卷. 北京: 中国水利水电出版 社, 2010.

[ 2 ] 周永娟, 仇江啸, 王 娇等. 三峡库区消落带生态环境脆弱性评价. 生态学报, 2010, 30(24): 672-673.

[ 3 ] 张 虹. 三峡重庆库区消落区基本特征与生态功能分析. 长江流域资源与环境, 2008, 17(3): 374-378.

[ 4 ] 王建超, 朱 波, 汪 涛. 三峡库区典型消落带淹水后草本植被的自然恢复特征. 长江流域资源与环境, 2011, $20(5): 603-610$.

[ 5 ] Mitsch WJ, Lu JJ, Yuan XZ et al. Optimizing ecosystem services in China. Science, 2008, 322 : 528.

[ 6 ] Zhang QF, Lou ZP. The environmental changes and mitigation actions in the Three Gorges Reservoir region, China. Environmental Science and Policy, 2011, 14(8):1132-1138.

[ 7 ] 罗芳丽, 王 玲, 曾 波等. 三峡库区岸生植物野古草 (Arundinella anomala Steud.) 光合作用对水淹的响应. 生 态学报, 2006, 26(11) : 3602-3609.

[ 8 ] 王海峰, 曾 波, 李 娅等. 长期完全淹水对 4 种三峡库区岸生植物存活及恢复生长的影响. 植物生态学报, 2008, 32(5) : 977-984.

[ 9 ] 王 欣, 高贤明. 模拟水淹对三峡库区常见一年生草本植物种子萌发的影响. 植物生态学报, 2010, 34 (12): 1404-1413.

[10］王晓荣, 程瑞梅, 肖文发等. 三峡库区消落带水淹初期地上植被与土壤种子库的关系. 生态学报, 2010, 30(21): 5821-5831.

[11] 张金洋, 王定勇, 石孝洪. 三峡水库消落区淹水后土壤性质变化的模拟研究. 水土保持学报, 2004, 18 (6): 120-123.

[12］李苑劼, 吕平毓. 三峡库区沉积物中重金属元素测定的前处理方法研究. 三峡环境与生态, 2011, 33(1): 18-20.

[13］储立明, 常 超, 谢宗强等. 三峡水库蓄水对消落带土壤重金属的影响. 土壤学报, 2011, 48(1): 192-196.

[14] 孙 荣, 袁兴中, 刘 红等. 三峡水库消落带植物群落组成及物种多样性. 生态学杂志, 2011, 30(2): 208-214.

[15] 常 超, 谢宗强, 熊高明等. 三峡水库蓄水对消落带土壤理化性质的影响. 自然资源学报, 2011, 26 (7): 1236-1244.

[16] 王 强, 袁兴中, 刘 红等. 三峡水库 $156 \mathrm{~m}$ 蓄水后消落带新生湿地植物群落. 生态学杂志, 2009, 28(11): 2183-2188.

[17] Pollock MM, Na iman RJ, Hanley TA. Plant species richness in riparian wetlands: a test of biodiversity theory. Ecology, 1998, 79: 94-105.

[18 ] Ferreira LV, Stohlgren TJ. Effects of river level fluctuation on plant species richness, diversity, and distribution in a flood plain forest in central Amazonia. Oecologia, 1999, 120: 582-587.

[19] 陈求稳, 欧阳志云. 流域生态学及模型. 生态学报, 2005, 25 (5) : 1153-1161.

[20] Lyon J, Gross NM. Patterns of plant diversity and plant environmental relationships across three riparian corridors. Forest Ecology and Management, 2005, 204: 267-278.

[21] Gordon E, Meentemeyer RK. Effects of dam operation and land use on stream channel morphology and riparian vegetation. Geomorphology, 2006, 82 : 412-429. 
[22] Lu ZJ, Li LF, Jiang MX. Can the soil seed bank contribute to revegetation of the drawdown zone in the Three Gorges Reservoir region? Plant Ecology, 2010, 209: 153-165.

[23] 杜高赞, 高美荣. 三峡库区典型消落带土壤粒径分布及分形特征. 南京林业大学学报: 自然科学版, 2011,35 (1) : 47-50.

[24] 中国长江三峡集团公司水情信息, 宜昌. http://www. ctgpc. com. cn/inc/sqsk. php.

[25] 方精云, 沈泽吴, 唐志尧等. 中国山地植物物种多样性调查计划及若干技术规范. 生物多样性, 2004, 12(1): $5-9$.

[26] 于 波, 严志远, 杨乐山等. $\mathrm{X}$ 射线菼光光谱法测定土壤和水系沉积物中碳和氮等 36 个主次痕量元素. 岩矿测 试, 2006, 25(1): 74-78.

[27] 白宝伟, 王海洋, 李先源等. 三峡库区淹没区与自然消落区现存植被的比较. 西南农业大学学报, 2005, 27 (5): 684-691.

[28] 胡 波, 张平仓, 任红玉等. 三峡库区消落带植被生态学特征分析. 长江科学院院报, 2010, 27(11): 81-85.

[29] 卢志军, 李连发, 黄汉东等. 三峡水库蓄水对消涨带植被的初步影响. 武汉植物学研究, 2010, 28(3): 303-314.

[30] 王 勇, 吴金清, 黄宏文等. 三峡库区消涨带植物群落的数量分析. 武汉植物学研究, 2004, 22(4): 307-314.

[31] Grime JP. Plant strategies, vegetation processes, and ecosystem properties: 2nd edition. New York: John Willey and Sons Ltd. , 2001.

[32] Casanova MT, Brock MA. How do depth, duration and frequency of flooding influence the establishment of wetland plant communities? Plant Ecology, 2000, 147: 237-250.

[33] Liu GH, Li EH, Yuan LY et al. Landscape scale variation in the seed banks of floodplain wetlands with contrasting hydrology in China. Freshwater Biology, 2006, 51: 1862-1878.

[34] 唐罗忠, 生原喜久雄, 户田浩人等. 湿地林土壤的 $\mathrm{Fe}^{2+}$, $\mathrm{Eh}$ 及 $\mathrm{pH}$ 值的变化. 生态学报, 2005, 25(1): 103-107.

[35] 黄昌勇. 土壤学. 北京: 中国农业出版社, 2000.

[36] 白军红, 邓 伟, 张玉霞等. 洪泛区天然湿地土壤有机质及氮素空间分布特征. 环境科学, 2002, 23(2): 77-81.

[37] 夏汉平, 余清发, 张德强. 鼎湖山 3 种不同林型下的土壤酸度和养分含量差异及其季节动态变化特性. 生态学 报, $1997,17(6): 645-653$.

[38 ] Beck MA, Elsenbeer H. Biogeochemical cycles of soil phosphorus in southern Alpine spodosols. Geoderma, 1999, 91: 249-260. 